\title{
Sheltered Children's Psychological Suffering and Carers' Lack of Training: Observations from a Brazilian Sheltered Home
}

Ariane F. Andrade ${ }^{1}$

Geraldo A. Fiamenghi-Jr' ${ }^{2^{*}}$

\section{UNIFAAT, Brazil \\ Email:arianneandradee@outlook.com \\ UNIFAAT and PUC-Minas, Brazil \\ Email:geraldoafj@gmail.com}

Licensed:

This work is licensed under a Creative Commons Attribution 4.o License.

Keywords:

Shelter

Child

Carer

Lack of expertise

Psychological suffering.

\begin{abstract}
This work aimed to investigate issues present in sheltered institutions for children. Main points are related to the reality of sheltering, as well as discussions on the role of carers and their lack of expertise concerning psychological development of sheltered children. Five 2hour weekly observations were conducted and 21 3-to-17-year-old children were observed, as well as their carers. Results pointed to carers' lack of expertise, depriving children of playing and exploring the environment, incapacity of establishing a dialogue with the children, inability to deal with disabled children, exposing children to peers, as well as absence of any sort of affection towards the children. Stemming from the carers' lack of expertise, it is important to reflect on training and support to institutions in the sense that they should not be forced to resort to untrained carers who might jeopardize the sheltered children's affective and social development.
\end{abstract}

\section{Introduction}

This research aimed to discuss the process of sheltering of a child, considering the lack of ability and training of carers to deal with the child's psychological suffering. Sheltering happens when the child is exposed to physical and psychological aggression, sexual abuse, neglect or social vulnerability. Institutionalization is both bad and good for the children; beneficial for it rescues the children from an abusive environment to a place where their protection is granted; harmful in the sense that children suffer for being apart from the family and from known people. Most institutions are considered total (Goffman, 1961) as they deprive the sheltered children from their freedom of choice, resulting in limitations to autonomy, according to Psychoanalysis (Oliveira, 2014). According to Brazilian legislation for children and teenagers (Brazil, 2013) sheltering should offer an individualized support in small groups, where they could establish bonds that support their development.

Carers are fundamental for their role in representing substitutive maternal and paternal functions and they must be able to listen, to talk, to protect, to play, to ensure the adequate development of the children they care for.

\subsection{Institutionalization and Carers}

According to Brazilian legislation (Brazil, 2013) institutional sheltering for children and teenagers is an atypical measure, for a short period of time, as a transition to fostering homes.

Concerning the carers, their role in children and teenagers' education, basic care, playing and affective relations, protection and socialization is fundamental throughout the institutionalization period to make it possible for them to develop as integral beings (Nogueira \& Costa, 2005). Besides, every single detail inside the institution is important, such as the physical structure, furniture, toys, but more importantly, the presence of a carer who is psychologically available to the child he/she is responsible for France (2010).

There is a need for professional training of carers in sheltered homes, in the sense that they may feel their work respected, their salary is fair (Halpern, Leite, \& Moraes, 2015) and their daily actions be meditated on, for them to understand the impact they have in children's development (Moré \& Sperancetta, 2010). The reason is that, although the carers must establish a bond with the children, helping the building of a family environment, they need to avoid feelings of ownership for the children, as they are supposedly sheltered for a brief period of time, till a foster family is found, or they are adopted (Halpern et al., 2015).

Recruitment process for carers to work in sheltered homes, although prescribing specific criteria for candidates, such as ability to deal with children and teenagers, to work in groups and capacity to mediate conflicts (Halpern et al., 2015) does not follow those directives in practice. Besides, there is the need for meetings and opportunities to listening and hearing of carers' needs to overcome difficulties. In the absence of 
such opportunities, they resort to informal talks that do not fill the gaps caused by anxiety and difficult situations the carers face in daily activities. In fact, there are many adverse conditions that affect carers work, such as work overload, shortage of staff and low salaries.

\subsection{Psychological Suffering of Sheltered Children}

Sheltered children are really suffering deprivation due to different situations, such as neglect, abuse, or lack of resources within the family to raise them (Nogueira \& Costa, 2005). As a result, many of the children tend to develop an attachment to carers within the institution, as a consequence of their mothers' absence (Alexandre \& Vieira, 2004).

If the carer is not prepared to receive the child and allow bonding to develop, the children will suffer, as they are not able to deal with anxiety and lack of support, resulting in psychological complications.

Barros and Fiamenghi-Jr (2007) state that the carer is the mediator of many of the children's attitudes towards life, such as attention, curiosity, cognition, language, emotions. In fact, it can be noted that sheltered children are always seeking for attention and care (Rivaben \& Fiamenghi-Jr, 2014).

However, studies showed that in most cases children and carers relationships are marked by despair, authoritarianism, repression and lack of affection (Barros \& Fiamenghi-Jr, 2007). There is indeed a significant difference in the Children's Depression Inventory scores with sheltered children and teenagers showing more depression compared to the ones living with families (Dell'Aglio \& Hutz, 2004).

\section{Method}

This research was based in observations conducted in an institution in a country town in Brazil. The home shelters approximately 21 children, from 3 to 17 years of age, boys and girls, who were separated from their families due to vulnerability, physical and verbal aggressions. 4 observations, lasting 2 hours each one, were conducted inside the institution's TV room. The institution's director signed a letter of consent, allowing the observations to be conducted, with the condition of keeping the anonymity of identification of the institution, the children and the carers. The research is part of a larger project, and it was approved by the Ethics Committee (CAAE 0024.0.272.000-08).

\section{Results}

Although the institution allowed the observations, the carers only permitted the observers to stay inside the TV room, where the younger children were kept watching TV, or eventually at the door facing the patio. There were normally 10 or more children inside the room and they should stay there quiet, watching cartoons.

During the period of observation, it could be noticed that carers never received any professional qualification, were unable to deal with disabled children, and spent most of the time chatting to each other, or using mobile phones. Their interference with the children's activities were summarized in calling their attention if they leave their places in the room. The children were not allowed to play, run, talk, interact with others, and were bullied by the carers, in front of their peers, as the following extracts of the observations show.

\section{Observation 1}

1. One of the male carers said that a boy had broken a lamp while kicking a ball, and it was an expensive one and suggested that the boy to pay for it, humiliating the boy in front of the others. It was obvious that the boy did not have financial means to pay for the object.

2. A female carer complained that the TV cartoons were boring and she could not stand them anymore, so she suggested the children to go to the patio, but they should pay attention not to break any other object.

3. The boy who broke the lamp was very sad, with his head down and the chief carer came in his direction started mocking the boy, who covered his head, trying to avoid crying and shame.

\section{Observation 2}

1. Two of the carers who were in the TV room, were playing with their mobile phones, and talking to each other the gossips in their social networks. If the children asked them to see what they were doing, they refused. They were talking and laughing.

2. One of the male carers asked what they were doing and they said it was "women's business", not for him to participate.

3. The children were very curious about the subject, but were simply ignored.

\section{Observation 3}

1. A deaf boy signed one of the carers and she said she did not understand what he wanted.

2. A younger boy came near and the deaf boy signed again. The little boy said to the carer that the deaf one wanted to go to the toilet to blow his nose.

3. The carer agreed to allow the boy to go to the toilet. 


\section{Observation 4}

1. A disabled boy started to wriggle in his wheelchair, with an expression of suffering in his face, but without any sound. No one of the carers even looked at him.

2. A deaf boy run to him, and showed the carer that the disabled boy was suffering, but she manifested no reaction.

The children, faced with such an amount of reproach, spent most of the time asking to play, to go to the patio, whispering to each other to prevent reprehension, watching TV, or sitting still on the chairs.

\section{Discussion}

The shelter home is a place for temporary accommodation with protective measures that should offer a welcoming environment and institutional condition to service within dignity standards, as well as emotional care (Brazil, 2013). However, observations shower lack of caring, especially emotional, as carers deprived the children of everything, exposed them to degrading situations, making them feel worse than ever, as shown in Observation 1, when the boy was humiliated after unintentionally breaking a lamp.

The carers never showed affective or supportive behaviors towards the children, such as allowing them to walk, play, talk, teaching without exposing them, or taking care of a disabled child. As a result, children called their attention even more, hoping to be noticed. They helped each other, played and whispered, in order to share affection. As Rivaben and Fiamenghi-Jr (2014) state, sheltered children are always searching for attention and care. Dell'Aglio and Hutz (2004) pointed that a great number of sheltered children presented depression, as well as other psychological difficulties, as a result of the lack of affective involvement of the carers.

According to Conanda/CNAS (2008) and Halpern et al. (2015) carers' work should be guided by the training manual, previous experience, qualification, fair payment, supervision, space for dialogue and psychological support. The sheltered home did not abide by those recommendations, as the carers were not trained to deal with disabled children, for example, as the observations showed. Psychological support was nonexistent, for the carers took out their anger in the children.

Children were not allowed to play, to go to the patio, and could only stay inside the TV room, whispering to each other, otherwise they would be rebuked, in total disagreement with the advice of Conanda/CNAS (2008) and Halpern et al. (2015).

The observed institution reports being a charity, and receives donations to keep their doors opened. Consequently, they hire inexperienced carers, able to "work for love", free time, with a workload in shifts of 12 by 36 hours. Those carers' "acts of love" resulted in lack of training to work with children, and their only aim was to keep the children quiet, paralyzed with fear of being scolded, generating anxiety, for they were already experience the distance from their families and the desire of being part of a home again.

Children do not understand that the carer is not able to take care of them and the institution is also inept to do it. A network of affective and social support is cardinal for children to develop adequately (Alexandre \& Vieira, 2004).

\section{Conclusion}

This research allowed understanding how carers work inside a sheltered home for children.

The institution where the observations took part is a nonprofit organization, that shelters children and teenagers living in situations of neglect, social vulnerability, physical, psychological and sexual abuse and is ruled by the Children and Adolescents' Law (Brazil, 2013). That legislation promulgates that children must have adequate shelter inside a home similar to a family environment, with suitable socio-educational facilities. However, observations showed that carers were not trained to work under those circumstances and their attitudes hindered the psychological development of the children under their guard.

The lack of training was shown in absence of dialogue and relationship with the children, deprivation of playing situations, inability to deal with disabled children and use of mobile phones while working. As a result, children were confined inside a TV room, sitting quietly, without any possibility of expressing themselves.

The institution has the duty to train the carers on how to talk to the children, with the purpose of understanding them, discovering their needs and feelings, due to the fact that they are going through a period of suffering.

Besides, legislation requires the institution to provide a space to hear and supervision the carers, for they feel the burden of their activities, and have no one to turn to.

Therefore, it is fundamental that training be provided for carers who are going to work with sheltered children, as well as support for the institutions, to prevent them of selecting unskilled employees, who may restrain the development of the children they are supposed to protect. 


\section{References}

Alexandre, D. T., \& Vieira, M. L. (2004). Relationship of attachment among institutionalized children living in a shelter situation. Psychology in Study. Maringá, 9(2), 207-217.

Barros, R. C., \& Fiamenghi-Jr, G. A. (2007). Affective interactions of sheltered children: An ethnographic study. Science and Collective Health, 12(5), 1267-1276.

Brazil. (2013). ECA- statute of the child and adolescent annotated and interpreted. Public Ministry of the State of Paraná. Center for Operational Support of Child and Adolescent Prosecutors. $6^{a}$. Ed.

Conanda/CNAS. (2008). Technical services for children and teenagers. Retrieved from http://www.mds.gov.br/cnas/noticias/orientacoes_tecnicas_final.pdf.

Dell'Aglio, D. D., \& Hutz, C. S. (2004). Depression and school performance in institutionalized children and adolescents. Psychology: Reflection and Criticism, 17(3), 341-350.

France, D. B. (2010). From shelter to shelter: Importance of attachment in institutional care. Brasília: Cradle of Citizenship.

Goffman, E. (1961). Asylums. New York: Anchor Books.

Halpern, E. E., Leite, L. M. C., \& Moraes, M. C. M. B. (2015). Selection, training and training of shelter staff: The gap between the prescribed and the actual. Work, Education and Health, 13(1), 91-113.

Moré, C. L. O. O., \& Sperancetta, A. (2010). Practices of social parents in institutions for the care of children and adolescents. Psychology and Society, 22(3), 519-528.

Nogueira, P. C., \& Costa, L. F. (2005). The child, the social mother and the shelter: Limits and possibilities. Brazilian Journal of Human Growth and Development, São Paulo, 15(3), 36-48.

Oliveira, J. P. (2014). The importance of caregivers in the process of institutionalization of sheltered children and adolescents - conclusion of the course. Faculty of Psychology at FAAT - Faculdades Atibaia.

Rivaben, M. L., \& Fiamenghi-Jr, G. A. (2014). Comparison of the intellectual level between institutionalized and noninstitutionalized children: A pilot study. Meeting: Journal of Psychology, 17(26), 157-164. 